\title{
Research of Voltage-Balancing Methods of Series-Connected IGBTs
}

\section{Lv Miao, Mei Guifang, Xu Guancheng, Dong Xiaoshuai}

Xi'an Xuji Power Electronic Technology Co. Ltd., Xi'an, China

\section{Email address:}

13630284819@163.com (Lv Miao),mei_gf@126.com (Mei Guifang),940771079@qq.com (Xu Guancheng), 1601000695@qq.com (Dong Xiaoshuai)

\section{To cite this article:}

Lv Miao, Mei Guifang, Xu Guancheng, Dong Xiaoshuai. Research of Voltage-Balancing Methods of Series-Connected IGBTs. Automation, Control and Intelligent Systems. Vol. 4, No. 5, 2016, pp. 73-79. doi: 10.11648/j.acis.20160405.11

Received: September 24, 2016; Accepted: October 12, 2016; Published: October 19, 2016

\begin{abstract}
Voltage-balancing method is the key to the application of series-connected Insulated-Gate Bipolar Transistor(IGBT). In this paper the voltage-balancing process is divided into 4 stages: dynamic turning-on process, dynamic turning-off process, the tail current state and steady state, whose voltage-balancing methods are then proposed respectively: gate compensation capacitor network for dynamic process; resistance capacitance(RC) voltage-balancing circuit designed for tail current state with the capacitance given by a formula; and parallel-connected voltage-balancing resistance for the steady state. Based on the work above, power module of two series-connected IGBTs is designed and tested under high voltage and high current condition. The result shows that under the series total voltage $2 \mathrm{kV}(1.85 \mathrm{kV}$ maximum peak voltage for each IGBT) and $2 \mathrm{kA}$ current, the power module balanced the voltage of the whole period of an turning on and off process, and both of the voltage-unbalance-rate of dynamic and steady state are less than $5 \%$.
\end{abstract}

Keywords: IGBT Series, Power Module, Dynamic Voltage Balancing, Tail Current

\section{Introduction}

With the development of power electronic technology, high voltage and high power equipments put forward higher request to the IGBT. However, because the structure and material of semiconductor devices, the voltage level of IGBT is the highest in $6.5 \mathrm{kV}$, which cannot reach the voltage level on many occasions in the power system, so IGBT series is an inevitable choice for IGBT high voltage applications. The press pack IGBT has double side heat dissipation, and the current density is higher under the same voltage level, especially for use in series [1-3]. As the speed of IGBT is very fast and the device parameters cannot be completely consistent, voltage balancing is the key to the application of series-connected IGBTs [4-6].

The key reasons of series-connected IGBTs voltage unbalancing are the gate electrode driver signal is not synchronous or the parameter is difference. As shown in Figure 1, with two series-connected IGBTs $\left(\mathrm{Q}_{1}, \mathrm{Q}_{2}\right)$ as an example, $U_{n}$ is the average steady-state voltage of each series-connected IGBTs. You can achieve voltage balancing if each series-connected IGBTs collector emitter voltage changes at the same time and the slope is the same, that is, to minimize $\Delta \mathrm{t}_{\mathrm{on}}, \Delta \mathrm{t}_{\text {off }}$ and the slope of $\left.\Delta \frac{\mathrm{d} v}{\mathrm{~d} t}\right|_{\mathrm{Q}_{1}-\mathrm{Q}_{2}}$ between collector and emitter. The dynamic voltage unbalancing of series devices [7] can be expressed as $\alpha_{\text {off }}=\frac{\Delta U_{n}}{U_{n}} \times 100 \%$.

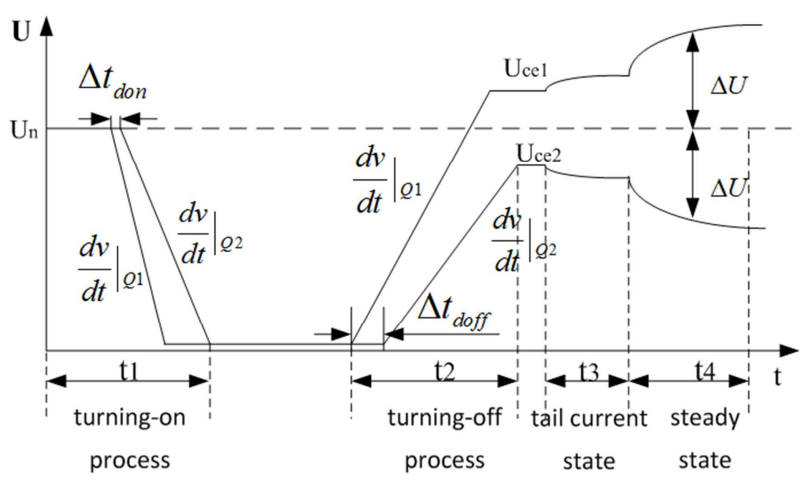

Figure 1. Diagram of voltage unbalance during the whole turning on and off period of $I G B T$.

As the IGBT series is mainly focused on the dynamic 
process of turn-off, but not the whole process. The control strategies including the passive buffer circuit [8], gate electrode signal delay control [9], gate electrode synchronous control [10], gate electrode voltage control [11], IGBT gate electrode balanced nuclear complex control circuit [12], IGBT Miller effect control voltage balancing technology [13]. These methods can be divided into active control directly and passive control indirectly. Active controlthrough bya closed-loop feedback control circuitofcollector emitter and gate electrode drive signal, which is complicated and high cost. Passive control through by introduction of RCDbuffer circuit in the peripheral IGBT, but cost greatly and efficiency low in the high frequency.

With the development of digital technology and high-speed optical transmission technology, the difference gate electrode drive between the synchronous signal is further reduced, and IGBT parameters are the main factors to IGBT series voltage balancing. Therefore, a new gate electrode control circuit is required to achieve the series-connected IGBTs voltage balancing.

In this paper the voltage balancing process is divided into 4 stages: dynamic turning-on process, dynamic turning-off process, the tail current state and steady state, whose voltage-balancing methods are then proposed respectively: gate compensation capacitor network for dynamic process; RC voltage-balancing circuit designed for tail current state with the capacitance given by a formula; and parallel-connected voltage-balancing resistance for the steady state. Based on the work above, power module of two series-connected IGBTs is designed and tested under high voltage and high current condition. The result shows that under the series total voltage $2 \mathrm{kV}(1.85 \mathrm{kV}$ maximum peak voltage for each IGBT) and $2 \mathrm{kA}$ current, the power module balanced the voltage of the whole period of an turning on and off process, and both of the voltage unbalance-rate of dynamic and steady state are less than $5 \%$.

\section{The Voltage Unbalancing Factor of Series IGBT in the Switching Cycle}

The voltage unbalancing process of the series-connected IGBTs can be divided into 4 stages in the whole period of a turning on and off process. As shown in Figure 1, the main reason of voltage unbalancing is $t_{\text {on }}$ and the down slope of $\frac{\mathrm{d} v}{\mathrm{~d} t}$ are not the same in $\mathrm{t}_{1}$. The main reason of voltage unbalancing is $\mathrm{t}_{\text {off }}$ and the rising slope of $\frac{\mathrm{d} v}{\mathrm{~d} t}$ are not the same in $t_{2}$. The main reason is $\mathrm{RC}$ for the tail current state not the same in $t_{3}$. The main reason is leakage current is not consistent for the steady state in $\mathrm{t}_{4}$.

\subsection{Voltage Unbalancing of Dynamic Turning-on Process}

The main reason of voltage unbalancing is $t_{o n}$ and the down slope of $\frac{\mathrm{d} v}{\mathrm{~d} t}$ are not the same in dynamic turning-on process.

Input capacitance of gate electrode is charged by the driving power supply in the turning-on process, the turning-on time is [14]:

$$
t_{\mathrm{don}}=R_{\mathrm{gon}} \times\left(C_{\mathrm{ge}}+C_{\mathrm{gc}}\right) \times \ln \frac{U_{\mathrm{cc}}}{U_{\mathrm{cc}}-U_{\mathrm{ge}(\mathrm{th})}}
$$

To the IGBT and the driver selected, the threshold voltage $\mathrm{U}_{\mathrm{ge}(\mathrm{th})}$ and the amplitude of the driving power supply $\mathrm{U}_{\mathrm{cc}}$ can be fixed, so ton is affected by the gate electrode drive resistance $\mathrm{R}_{\text {gon }}$, g-e capacitance $C_{g e}$ and g-c capacitance $C_{g c}$ and so on. Then to reduce the difference between $C_{g e}$ and $C_{g c}$ of IGBT as soon as possible can ensure $t_{\text {don }}$ is basically synchronous.

When the $U_{c e}$ of IGBT rapidly dropped, $C_{g c}$ changed with $U_{c e}$ can be approximate equivalent as shown in Figure 2 below [15]:

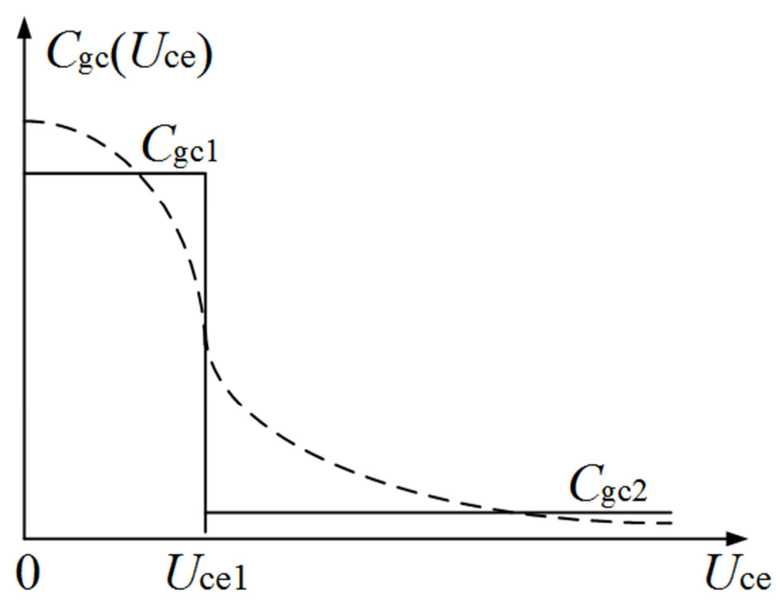

Figure 2. Principle of the $C_{g c}$ with $U_{c e}$.

At the same time, the approximate expression of the down slope of $U_{c e}$ is as follows [16]:

$$
\frac{\mathrm{d} U_{\mathrm{ce}}}{\mathrm{d} t} \approx\left\{\begin{array}{cc}
-\frac{U_{\mathrm{cc}}-U_{\text {mill_on }\left(I_{\mathrm{c}}\right)}}{R_{\mathrm{gon}} \times C_{\mathrm{gc} 2}} & U_{\mathrm{ce}} \geq U_{\text {cel }} \\
-\frac{U_{\mathrm{cc}}-U_{\text {mill_on }\left(I_{\mathrm{c}}\right)}}{R_{\mathrm{gon}} \times C_{\mathrm{gcl}}} & U_{\mathrm{ce}}<U_{\text {cel }}
\end{array}\right.
$$

As shown above, $U_{\text {mill_on (Ic) }}$ is the amplitude of the gate Miller level in the turning-on process, which is related with $I_{c}$. For the series of IGBT, $I_{c}$ is equal, so it can be considered that $U_{\text {millon (Ic) }}$ is the equal. Then voltage decline rate is mainly affected by $\mathrm{R}_{\mathrm{gon}}$ and $C_{g c}$ in the dynamic turning-on process.

\subsection{Voltage Unbalancing of Dynamic Turning-off Process}

Similar to the turning-on process, total input capacitance of gate electrode is charged by the driving power supply in the turning-off process, the turning-off time is[14]: 


$$
t_{\mathrm{doff}} \approx R_{\mathrm{goff}} \times\left(C_{\mathrm{ge}}+C_{\mathrm{gc}}\right) \times \ln \left(\frac{U_{\mathrm{cc}}-U_{\mathrm{gg}-}}{U_{\text {mill_off }\left(I_{\mathrm{c}}\right)}-U_{\mathrm{gg}-}}\right)
$$

$U_{g g-}$ is the driver's turn off voltage. Toff is affected by the gate electrode drive resistance $\mathrm{R}_{\text {goff, }}$ g-e capacitance $C_{g e}$ and g-c capacitance $C_{g c}$ and so on.

At the same time, the approximate expression of the rising slope of $U_{c e}$ is as follows:

$$
\frac{\mathrm{d} U_{\mathrm{ce}}}{\mathrm{d} t} \approx\left\{\begin{array}{l}
\frac{U_{\text {mill_off }\left(I_{\mathrm{c}}\right)}-U_{\mathrm{gg}-}}{R_{\mathrm{goff}} \times C_{\mathrm{gc} 1}} U_{\mathrm{ce}} \leq U_{\mathrm{ce} 1} \\
\frac{U_{\text {mill_off }\left(I_{\mathrm{c}}\right)}-U_{\mathrm{gg}-}}{R_{\mathrm{goff}} \times C_{\mathrm{gc} 2}} U_{\mathrm{ce}}>U_{\mathrm{ce} 1}
\end{array}\right.
$$

Then voltage rising rate is mainly affected by $\mathrm{R}_{\mathrm{goff}}$ and $C_{g c}$ in the dynamic turning-off process.

In summary, the main factors that affect the dynamic voltage balancing of IGBT are shown in Table 1:

Table 1. Factors affecting the dynamic voltage-balancing process of IGBT.

\begin{tabular}{lcl}
\hline variable & & influence factor \\
\hline \multirow{3}{*}{ turning-on } & $t_{\mathrm{don}}$ & $R_{\mathrm{gon}}, C_{\mathrm{ge}}, C_{\mathrm{gc}}$ \\
& $\frac{\mathrm{d} v}{\mathrm{~d} t}$ & $R_{\mathrm{gon}}, C_{\mathrm{gc}}$ \\
& $t_{\mathrm{doff}}$ & $R_{\mathrm{gon}}, C_{\mathrm{gc}}$ \\
turning-off & $\mathrm{d} v$ & $R_{\mathrm{goff}}, C_{\mathrm{ge}}, C_{\mathrm{gc}}$ \\
& $\mathrm{d} t$ & $R_{\mathrm{goff}}, C_{\mathrm{gc}}$ \\
\hline
\end{tabular}

According to the analysis above, the dynamic parameters that affect the IGBT in the turning-off process can be divided into two types of external parameters and internal parameters. The external parameters include $I_{c}$, drive voltage $U_{c c}$ and $U_{g g \text {-, }}$, gate electrode resistance $\mathrm{R}_{\mathrm{g}}$. The internal parameters include $C_{g e}$ and $C_{g c}$. Further, $\mathrm{I}_{c}, U_{c c}$ and $U_{g g-}$ can be considered equal. Both $\mathrm{R}_{\mathrm{gon}}$ and $\mathrm{R}_{\mathrm{goff}}$ are adjustable. Then the key factor affect the dynamic voltage unbalancing is the difference of $C_{g e}$ and $C_{g c}$ of IGBT.

Gate compensation capacitor network for dynamic process then proposed, that is parallel-connected voltage-balancing capacitor between gate electrode and emitter to weaken the inconsistency of the $C_{g e}$ of the IGBT, and parallel-connected voltage-balancing capacitor between gate electrode and collector to weaken the inconsistency of the $C_{g c}$ of the IGBT. Because the parallel capacitor will cause IGBT turn-on and turn-off time longer, the need for the dynamic characteristics optimization is reduce driving resistance of $\mathrm{R}_{\text {gon }}$ and $\mathrm{R}_{\text {goff }}$ in order to make ton and toff unchanged.

\subsection{Voltage Unbalancing of the Tail Current State}

When the gate voltage of $U_{g e}$ is reduced to below the threshold voltage, the collector current $I_{c}$ get into the tail current stage.

As the IGBT parameters may not be completely consistent, the current stage of tail attenuation also cannot be exactly the same, which result in voltage unbalancing of IGBT series. As two series-connected IGBTs as an example, the voltage unbalancing of the tail current state as shown in figure 3.

At this time, the gate driver lost control of the IGBT, only can through $\mathrm{RC}$ voltage-balancing circuit designed for tail current state to improve voltage unbalancing.

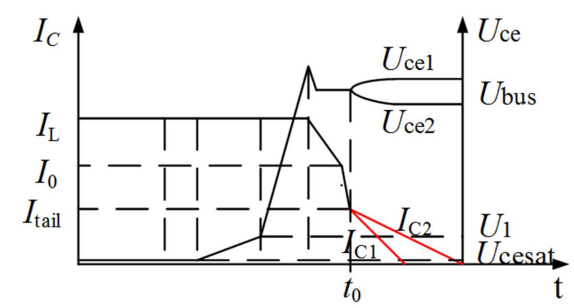

Figure 3. Diagram of voltage unbalance during tail current process of series-connected IGBTs.

Assume that the decay rate of $\mathrm{Q}_{1}$ is greater than $\mathrm{Q}_{2}$, and the voltage $U_{c e l}$ of $\mathrm{Q}_{1}$ being to rise and $U_{c e 2}$ of $\mathrm{Q}_{2}$ being to decline, and the decline of the tail current decay is approximate to exponential function, and the tail current time constant is $\tau_{1}$ and $\tau_{2}$ of the two series-connected IGBTs respectively.

Assume that the current is $\mathrm{I}_{0}$ flows through the IGBT when the $t_{0}$ time, and voltage unbalancing all absorbing by capacitance $\mathrm{C}$ caused by the tail current. Ignore limiting current resistor $R_{s}$, the relationship between the voltage and current of the series IGBT is expressed as follows after $\Delta t$.

$$
\begin{aligned}
& C \times\left[U_{1}\left(t_{0}+\Delta t\right)-U_{1}\left(t_{0}\right)\right]= \\
& I_{0} \times\left(e^{-\frac{t_{0}}{\tau_{2}}}-e^{-\frac{t_{0}}{\tau_{1}}}\right) \times \Delta t+C \times\left[U_{2}\left(t_{0}+\Delta t\right)-U_{2}\left(t_{0}\right)\right]
\end{aligned}
$$

simplify as:

$$
C \times U_{1}^{\prime}=I_{0} \times\left(e^{-\frac{t_{0}}{\tau_{2}}}-e^{-\frac{t_{0}}{\tau_{1}}}\right)+C \times U_{2}^{\prime}
$$

And:

$$
U_{1}+U_{2}=U_{\mathrm{dc}}
$$

The voltage difference in the tail state of the series IGBT is:

$$
\Delta U=U_{1}-U_{2}=\frac{I_{0}}{C} \times\left(\int e^{-\frac{t_{0}}{\tau_{2}}} \mathrm{~d} t-\int e^{-\frac{t_{0}}{\tau_{1}}} \mathrm{~d} t\right)
$$

Assumed that the current decays to zero after $(4 \sim 5) \tau$, absorption capacity expressed as follows:

$$
C=\frac{I_{0}}{\Delta U} \times\left(\tau_{2}-\tau_{1}\right)
$$

\subsection{Voltage Unbalancing of the Steady State}

Parallel-connected voltage balancing resistance for the steady state in order to solve the static voltage of series IGBT imbalance when the IGBT is completely turned off.

According to the following formula select resistance [17]:

$$
R=\frac{1}{10} \times R_{\mathrm{off}}
$$




\section{Voltage Balancing Test of Series-Connected IGBTs Power Module}

\subsection{Parameters of Series-Connected IGBTs Power Module}

The power module number of the two series-connected IGBTs is 5 SNA2 $2000 \mathrm{~K} 451300$ of ABB, rated voltage is $4500 \mathrm{~V}$, rated current is $2000 \mathrm{~A}$.

1) Selected for Cge and $\mathrm{Cgc}$

According to the IGBT datasheet [18], combined with the analysis of the 2.2 section, select $C_{g e \text { ext }}=300 \mathrm{nF}$ and $C_{\text {gc_ext }}=1.5 \mathrm{nF}$.

2) Selected for Rs and $\mathrm{C}$

According to IEC 60747-9:2007, the continuous time of the tail current of the IGBT comes from 0.1Ic to 0.02Ic. Then the start of the tail current time $I_{\text {tail }}=125 \mathrm{~A}$. Assumed that the difference of the tail current time constant is 0.5 us 1.0 us, and $U_{d c}$ is $2000 \mathrm{~V}$. In order to the voltage-unbalance-rate of dynamic and steady state are less than $5 \%$, as the formula (7), can calculate $\mathrm{C}=0.5 \mu \mathrm{F}$ or $1 \mu \mathrm{F}$. In practice, select $\mathrm{C}=0.56 \mathrm{uF}$.

Considering the loss and so on, select $\mathrm{R}_{\mathrm{s}}=36 \Omega$.

3) Selected for voltage balancing resistance $R$

According to the IGBT datasheet [18], the maximum leakage current is $100 \mathrm{~mA}$ at $125 \mathrm{C}$. According to the formula (8), the voltage balancing resistance $R=450 \mathrm{k} \Omega$.

As to the parameters mentioned above, the power module of the IGBT series is shown in Figure 4:

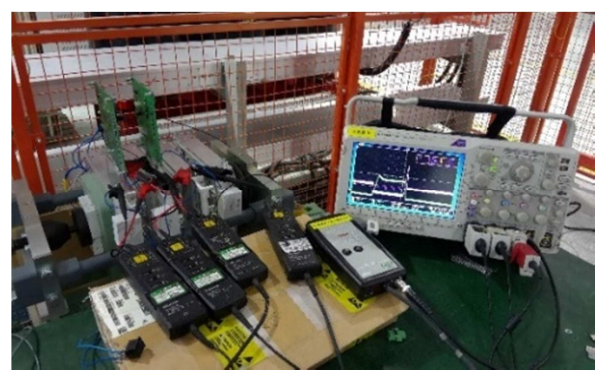

Figure 4. Equipment of series-connected IGBTs.

\subsection{Voltage Balancing Test of Series-Connected IGBTs Power Module}

The schematic of two series-connected IGBTs is shown in Figure 5. The bus voltage $U_{d c}=2000 \mathrm{~V}$, the load inductance $\mathrm{L}=141 \mathrm{uH}$, and the two series-connected IGBTs are $\mathrm{Q}_{1}$ and $\mathrm{Q}_{2}$, and $\mathrm{Q}_{3}$ is used as parallel-connected diode.

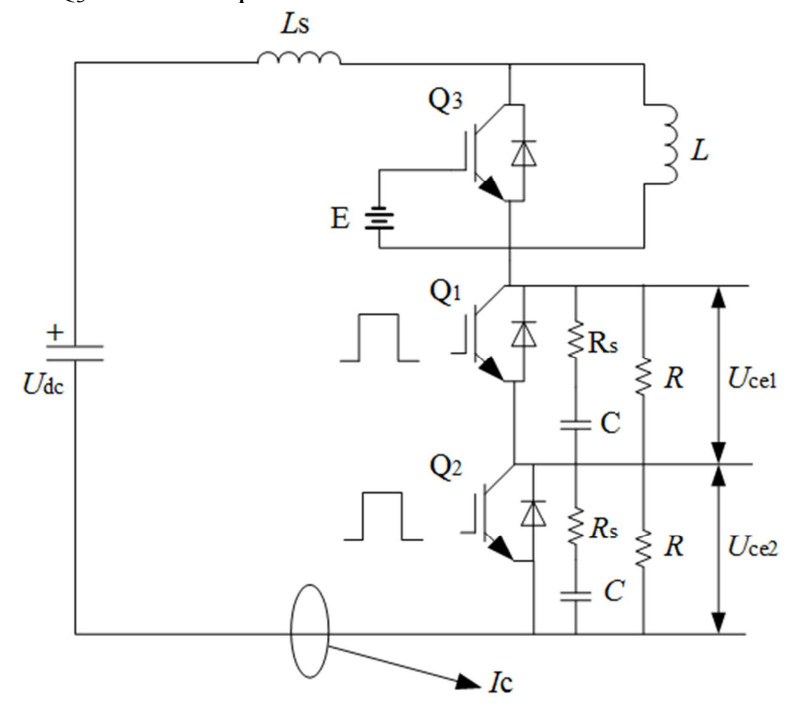

Figure 5. Schematic of two series-connected IGBTs.

The waveform of turning off process without voltage balancing measures as shown in Figure 6 below. As Figure 6 (a) can be seen, the voltage difference of two series IGBT in the turning-off process is $230 \mathrm{~V}$ without any voltage balancing measures, and the voltage-unbalance-rate of dynamic is $4.5 \%$. The inconsistent dynamic voltage exacerbates the voltage unbalancing in the tail current stage. Figure 6 (b) says that the voltage difference of two series IGBT in steady state is $1350 \mathrm{~V}$, and $\mathrm{Q}_{1}$ bear all voltage drop, $\mathrm{Q}_{2}$ turning-off failure, the voltage-unbalance-rate of steady state is as high as $100 \%$.

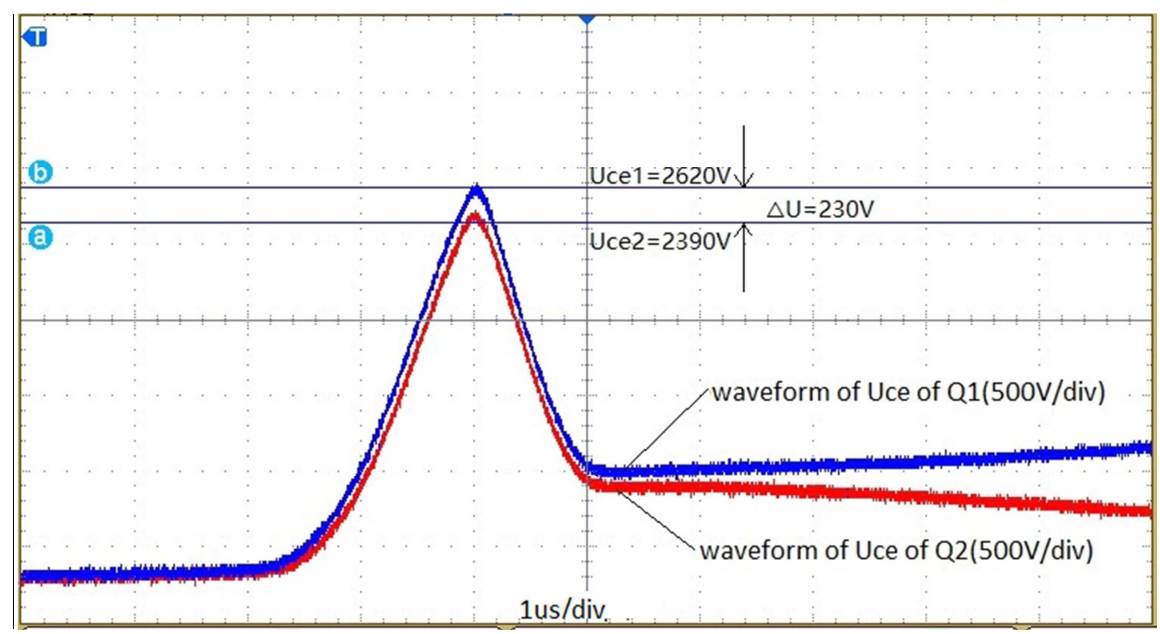

(a) Waveform of turning off process 


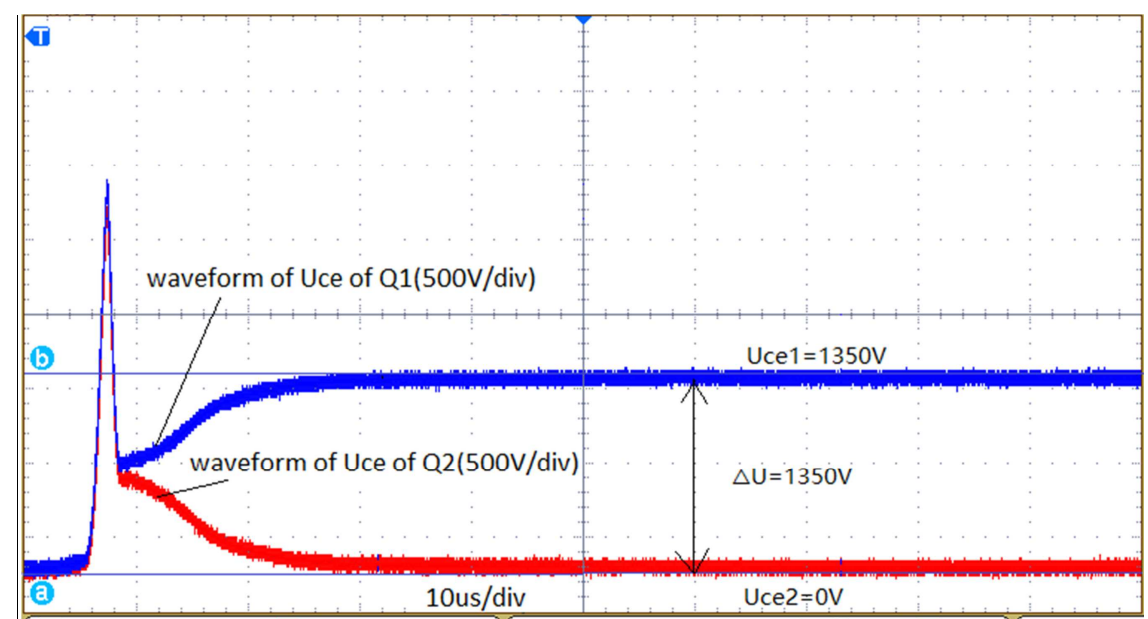

(b) Expanded waveform of turning off process

Figure 6. Waveform of turning off process without voltage balancing measures.

Waveform of turning off process of IGBT with gate compensation capacitor network when $C_{g e \_e x t}=300 \mathrm{nF}$ and $C_{g c \_ \text {ext }}=1.5 \mathrm{nF}$ but without voltage balancing resistance $\mathrm{R}$.

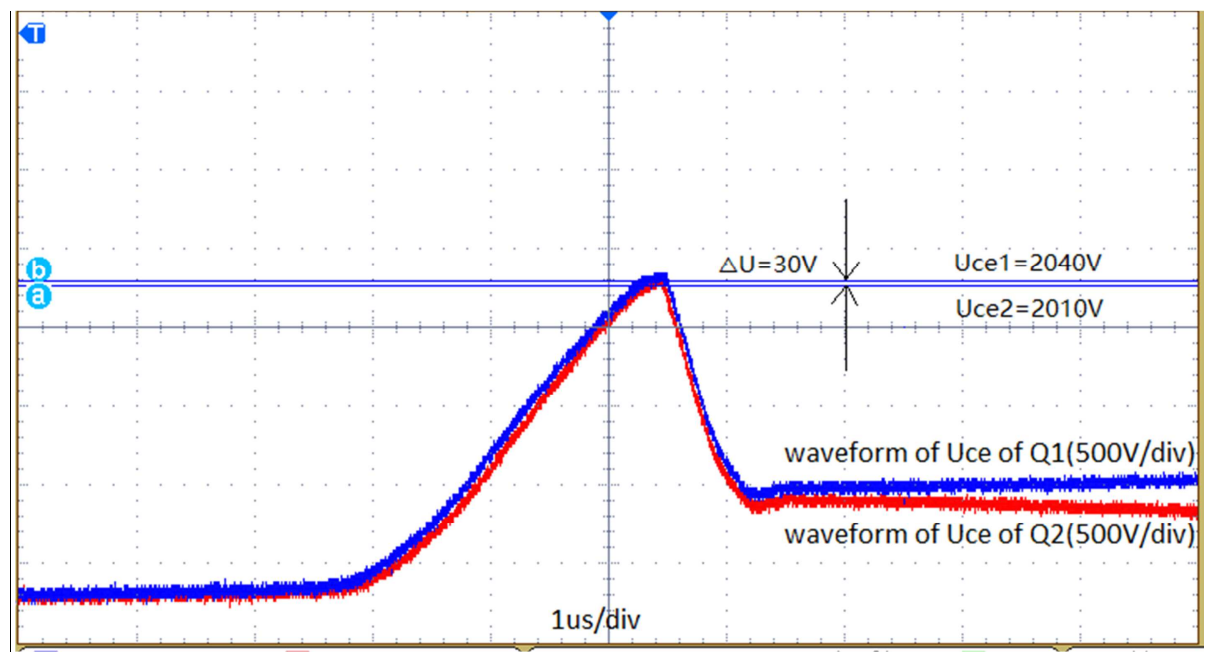

(a)Waveform of turning off process

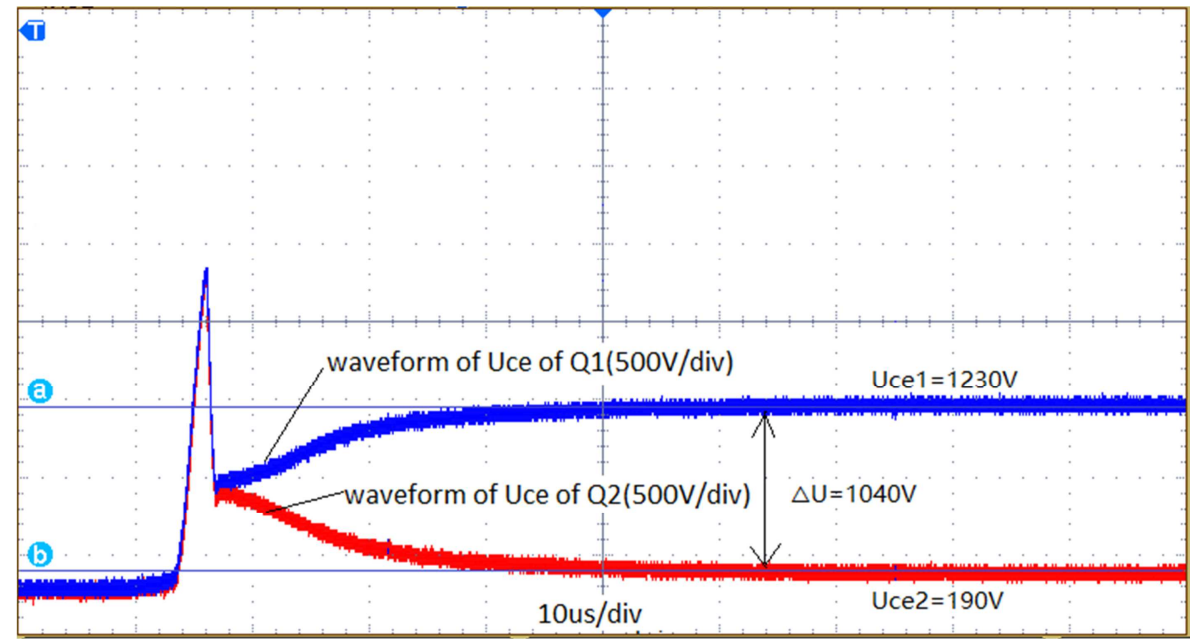

(b)Expanded waveform of turning off process

Figure 7. Waveform of turning off process of IGBT with gate compensation capacitor network. 
As Figure 7 (a) can be seen, the voltage difference of two series IGBT in steady state come from $230 \mathrm{~V}$ to $30 \mathrm{~V}$, and the voltage-unbalance-rate of dynamic is is less than $1 \%$. which improve the consistency of the delay time and the rising voltage rate when the gate compensation capacitor network used. Because of the increase of the dynamic voltage consistency weaken the influence of the voltage unbalancing of the steady state, the voltage difference of two series IGBT in steady state comes from $1350 \mathrm{~V}$ to $1040 \mathrm{~V}$ as Figure 7 (b), and the voltage-unbalance-rate of dynamic decline to $73.2 \%$. Waveform of turning off process with gate compensation capacitor network and RC circuit as shown in Figure 8. As can be seen, Waveform of dynamic peak voltage of two series-connected IGBTs is consistent, and voltage imbalance degree in steady state from $73.2 \%$ decline to $6.1 \%$.

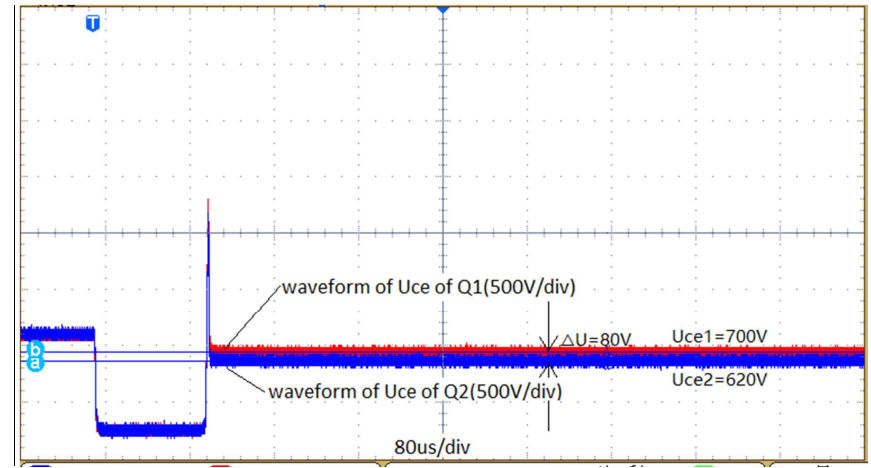

Figure 8. Waveform of turning off process with gate compensation capacitor network and RC circuit.

When the power module balanced the voltage of the whole turning on and off process is implemented, double pulse test the voltage balancing of the whole period of the IGBT, and voltage balancing resistance $\mathrm{R}$ used. Double pulse drive test waveform select $80 \mathrm{us}, 30 \mathrm{us}, 30 \mathrm{us}$, bus voltage $U_{d c}=2000 \mathrm{~V}$, double pulse waveforms of IGBT series are shown in figure 9.

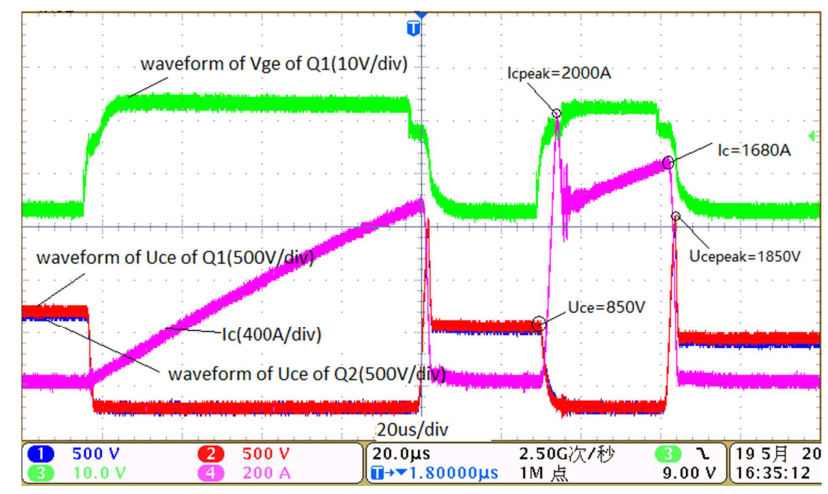

Figure 9. Waveform of the whole turning on and off process of series-connected IGBTS.

As can be seen figure 9 above, the current peak of the second turning-on time is $2000 \mathrm{~A}$, voltage Uce of each IGBT is $850 \mathrm{~V}$, and the turning-on waveform of the two series-connected IGBTs completely coincide. The voltage peak of the second turning-off time is $1850 \mathrm{~V}$ and the current of the second turning-off time is $1680 \mathrm{~A}$, and the turning-off waveform of the two series-connected IGBTs completely coincide. Considering the error of the high-voltage test is about $3 \%$, as can be seen above, the voltage and current of the series-connected IGBTs in the whole turning on and off process is completely coincident, and the voltage and current dynamic unbalance-rate are less than $5 \%$.

\section{Conclusion}

In this paper the voltage-balancing process is divided into 4 stages, the influence factors of each stage are summarized, and voltage-balancing methods are then proposed respectively. Based on the work above, power module of two series-connected IGBTs is designed and tested under high voltage and high current condition. The result shows that the power module balanced the voltage of the whole period of a turning on and off process according to the analysis and selected above, and both of the voltage-unbalance-rate of dynamic and steady state are less than 5\%. The method cost low and volume compact, which can improve the consistency of dynamic voltage of series IGBT significantly, and provides reference value for engineering application.

\section{Acknowledgements}

This paper is one of the stage results of the prototype of the flexible HVDC converter valve based on localization IGBT in the National Science and Technology Major Project of China (2015ZX02301003).

\section{References}

[1] S. Eicher, M. Rahimo, E. Tsyplakov, et al. $4.5 \mathrm{kV}$ press pack IGBT designed for ruggedness and reliability [C]. IEEE Industry Application Conference, 39th IAS Annual Meeting. 2004: 1534-1539.

[2] Dou Zechun, Rupert Stevens, XinLanyuan. et al. Design and characteristic analysis of novel press-contact IGBT module[J]. Electric Drive for Locomtives, 2013, 1(01): 10-13(in Chinese).

[3] Jin Rui, YuKunshan, Zhang Peng, et al. Development of IGBT devices and the typical application in the smart grid [J. Smart Grid, 2013, 01(02): 11-16(in Chinese).

[4] YU Hualong, LU Ting, JI Shiqi, YUAN Liqiang, ZHAO Zhengming. Active Clamping Circuit Threshold Voltage Design for Series-connected HVIGBTs [J]. Proceedings of the CSEE, 2016, 36(5): 1357-1365.

[5] Zhang Bingjing. Research on the unbalancing dynamic voltage of SerialPress-contact IGBT [D]. North China Electric Power University, 2014.03.

[6] Xingyu Li. The Research of Series Connected Diode Clamping IGBTEqualizing [D]. Beijing Institute of Technology, 2016.01.

[7] K. Sasagawa, Y. Abe, K. Matsuse. Voltage-blancing method for IGBTs connected in series [J]. IEEE Transactions on Industry Application, 2004, 40(4): 1025-1030. 
[8] Ning Dalong, Tong Xiangqian, Li Xia, et al. Design of RCD Active Gate Control Circuit for Series Connected IGBTs [J]. Transaction of China Electrotechnical Society, 2013, 28(2): 192-198.

[9] Soonwook H, Chitta V, Torrey D A. Series Connection of IGBT's with Active Voltage Balancing [J]. IEEE Transactions on Industrial Applications, 1999(35): 917-923.

[10] Consoli A, Musumeci S, Oriti G, et al. Active Voltage Balancement of Series Connected IGBTs [C]. Conference Record of the 30th IAS Annual Meeting, 1995, 13: 2752-2758.

[11] Patrick R Palmer, Enrico Santi, Jerry L Hudgins, et al. Circuit Simulator Models for the Diode and IGBT with Full Temperature Dependent Features [J]. IEEE Transactions on Power Electronics, 2003, 18(5): 1220-1229.

[12] Tong Xiangqian, Ning Dalong, Xia Wei, et al. Design of RCD Active Gate Control Circuit for Series Connected IGBTs [J]. Transaction of China Electrotechnical Society, 2013, 28(2): 192-198.

[13] Withanage R, Shammas N. Series Connection of Insulated Gate Bipolar Transistors [C]. Proceedings of European Power Electronics and Applications Conference, 2005: 10-19.
[14] PANG Hui, WEN Jialiang, HE Zhiyuan, et al. Unbalancing Voltage of High Power Series Connected IGBT Valve [J]. Proceeding of the CSEE, 2011, 31(21): 1-8.

[15] Petar J. Grobovic, An IGBT Gate Driver for Feed-Forward Control of Turn-on Losses and Reverse Recovery Current [J]. IEEE Transactions on power electronic, 2008, 23(02): 643-652.

[16] Igor Baraia, Jon Andoni Barrena, An Experimentally Verified Active Gate Control Method for the Series Connection of IGBT/Diodes [J]. IEEE transactions on power electronic, 2012, 27(02): 1025-1038.

[17] LIU Lei. Research on Voltage Balancing Techniques of Series-Connected IGBTs [D], Nanjing: Nanjing University of Aeronautics and Astronautics, 2009: 29-30.

[18] http://new.abb.com/semiconductors/insulated-gate-bipolar-tran sistor-(igbt)-and-diode-modules/stakpak. 